\title{
Whole Exome Sequencing as a Diagnostic Tool of Primary Complement Component Deficiencies: A Multicenter Experience of Three Novel Mutations
}

Oded Shamriz

Hadassah Medical Organization

Amos J Simon

Sheba Cancer Research Center

Shirly Frizinsky

Sheba Medical Center

Orli Megged

Shaare Zedek Medical Center

Ortal Barel

Sheba Medical Center

Yuval Tal

Hadassah Medical Center

Raz Somech

Sheba Medical Center

Ori Toker ( $\nabla$ oritoker@gmail.com )

Shaare Zedek Medical Center https://orcid.org/0000-0002-5248-3193

\section{Research Article}

Keywords: whole exome sequencing, meningococcal infection, meningococcemia, complement components.

Posted Date: May 4th, 2021

DOI: https://doi.org/10.21203/rs.3.rs-405295/v1

License: @ (i) This work is licensed under a Creative Commons Attribution 4.0 International License. Read Full License 


\section{Abstract}

Diagnosis of primary complement deficiencies requires a high index of suspicion. Thus, susceptible patients are often underdiagnosed and untreated. Here, we present a multi-center experience with three novel inborn errors of the classical complement system. This is a retrospective multicenter analysis of computerized medical records of children (>18 years) admitted in the period between 2003 and 2018 at Shaare Zedek Medical Center in Jerusalem and Edmond and Lily Safra Children's Hospital, Tel-Hashomer Medical Center, in Ramat Gan, Israel. Patients were genetically diagnosed by a complimentary immune work-up. We identified 5 patients ( 3 males) from four different consanguineous families harboring three novel mutations in the complement components C6-C8. Genetic mutations were identified by whole exome sequencing. Clinical manifestations consisted of meningitis with or without meningococcemia. The immune work-up demonstrated nearly absent levels of $\mathrm{CH} 50$, compatible with a complement pathway defect. The mean diagnosis delay was $10.56(0-30)$ years. Conclusion: Invasive meningococcal infections may be life-threatening and cause severe neurological sequela. Awareness of risk factors for primary complement deficiencies, even at the firs infectious episode, should facilitate prompt immune and genetic investigations, commencing diagnosis and proper treatment.

\section{What Is Known}

- Deficiencies in complement components increase susceptibility to invasive meningococcal infections.

- Recurrent meningococcal infections mandate a diagnostic work-up of the complement system.

\section{What is new:}

- Whole exome sequencing can be utilized for prompt genetic diagnosis of complement deficiencies.

- High rates of consanguinity, even in the presence of a single meningococcal infection, are indicative of a need for genetic and immune work-ups.

\section{Introduction}

The prevalence of primary complement component (C) deficiencies among patients with primary immune deficiencies (PIDs) is estimated to be $1-6 \%$, though higher rates have also been reported [1]. Decreased levels of terminal components C5-C9 are known to increase susceptibility to infection with Neisseria spp., including Neisseria meningitides [1]. Moreover, inherited disorders of regulators of the alternative pathway, such as properdin deficiency, are found in patients with recurrent meningococcal infections $[1 ; 2]$.

Clinical investigation of patients with recurrent meningococcal infections usually warrants screening complement activity by measuring the $50 \%$ hemolytic complement activity of serum ( $\mathrm{CH} 50)$ and the alternative pathway hemolytic assay (AH50), followed by quantification of $\mathrm{C} 1-\mathrm{C}$. This facilitates the treatment of susceptible patients with prophylactic antibiotics and meningococcal vaccination, reducing the risk of future invasive meningococcal infections. However, the diagnosis of complement deficiencies requires a high index of suspicion, especially when treating patients with a single infectious episode [3]. Such patients are often underdiagnosed and untreated until the next episode of meningitis or meningococcemia [4].

The introduction of next-generation sequencing has been a powerful tool in the diagnosis of inborn errors of immunity [5]. In addition, accumulating evidence suggests that whole exome sequencing (WES) is effective in promoting the diagnosis of complement deficiencies, such as C1Q deficiency, which induces the development of systemic lupus erythematosus (SLE) [6; 7].

Here, we present a multi-center experience of five patients with three novel inborn errors of the classical terminal complement system. We discuss the genetic and immune characteristics of these patients and review the corresponding literature.

\section{Materials And Methods Study design and population}

This retrospective multicenter analysis was based on the computerized medical records of pediatric patients (>18 years of age) admitted from $2003-2018$ to Shaare Zedek and Tel-Hashomer Medical Centers in Israel. Patients were genetically diagnosed by complimentary immune work-up.

\section{Immune work-up}

The immune work-up consisted of screening the complement system by measuring $\mathrm{CH} 50$, followed by quantifying $\mathrm{C} 1-\mathrm{C} 9$. Asplenia was ruled out by abdominal ultrasonography.

\section{Genetic work-up}

High throughput sequencing for whole exome sequencing was performed on genomic DNA samples from the patient. Coding regions were enriched with a SureSelect Human All Exon V5 Kit (Agilent) and then sequenced as 100-bp paired-end runs on an Illumina HiSeq 2500 (IIlumina Inc). We used the BWA mem algorithm (version 0.7.15)[8] for alignment of the sequence reads to the human reference genome (hg19 or Hg38). The HaplotypeCaller algorithm of GATK version 3.4 was applied for variant calling, as recommended in the best practice pipeline [9]. KGG-seq v.1.0 was used for annotation of identified variants [10] and in house scripts were applied for filtering, based on family pedigree and local dataset of variants detected in previous sequencing projects. All mutations of the complement genes were validated by dideoxy Sanger sequencing in the carriers and healthy control. Data were evaluated using Sequencer v5.0 software (Gene Codes Corporation). 


\section{Ethical review of the study}

This study was approved by the institutional review board committees of Shaare Zedek and Tel-Hashomer Medical Centers.

\section{Results}

\section{Clinical characteristics}

Patient characteristics are detailed in Table 1. We identified 5 patients ( 3 males and 2 females) from four different families (A-D). Consanguinity was noted in three of the families. Excluding P3, all patients were from a Jewish origin. Family history of recurrent meningococcal infections was notable in three patients (P1, P2, and P4). Representative pedigrees of families A and D are shown in Fig. 1A and B, respectively.

Table 1

Clinical characteristics of the patients

\begin{tabular}{|c|c|c|c|c|c|c|c|c|}
\hline Patient & Family & $\begin{array}{l}\text { Age } \\
\text { (diagnosis/ } \\
\text { presentation; } \\
\text { years) }\end{array}$ & Gender/ethnicity & Consanguinity & $\begin{array}{l}\text { Family history } \\
\text { of recurrent } \\
\text { meningococcal } \\
\text { infections }\end{array}$ & $\begin{array}{l}\text { Complement } \\
\text { component } \\
\text { impaired }\end{array}$ & Genetic mutation & $\begin{array}{l}\text { Clinical } \\
\text { presentation }\end{array}$ \\
\hline P1 & $A$ & $14 / 14$ & $\mathrm{~F} / \mathrm{J}$ & + & + & $\mathrm{C} 6$ & $\begin{array}{l}\text { c.C1786T; p.R596X } \\
\text { exon 12, } \\
\text { homozygous }\end{array}$ & $\begin{array}{l}\text { Meningococcemia, } \\
\text { meningitis }\end{array}$ \\
\hline P2 & & $20.5 / 2.5$ & $\mathrm{~F} / \mathrm{J}$ & & & & & $\begin{array}{l}\text { Meningococcemia, } \\
\text { meningitis }\end{array}$ \\
\hline P3 & B & $14.1 / 13.8$ & $\mathrm{M} / \mathrm{A}$ & - & - & $\mathrm{C} 7$ & $\begin{array}{l}\text { n.c.G1135C;p.G379R; } \\
\text { exon } 10 \text {, } \\
\text { homozygous }\end{array}$ & $\begin{array}{l}\text { Meningococcemia, } \\
\text { meningitis, right } \\
\text { perichondritis, } \\
\text { abducens palsy }\end{array}$ \\
\hline P4 & C & $9.5 / 5$ & $\mathrm{M} / \mathrm{J}$ & + & + & & & $\begin{array}{l}\text { Meningococcemia, } \\
\text { meningitis }\end{array}$ \\
\hline P5 & D & $37 / 7$ & $\mathrm{M} / \mathrm{J}$ & + & - & $\mathrm{C} 8 \mathrm{~b}$ & $\begin{array}{l}\text { c. } 361 \mathrm{C}>\mathrm{T} \text {, } \\
\text { p.Arg121Ter, exon } \\
3 / 12 \text {, homozygous }\end{array}$ & $\begin{array}{l}\text { Recurrent } \\
\text { meningococcal } \\
\text { meningitis, } \\
\text { recurrent } \\
\text { sinopulmonary } \\
\text { infections }\end{array}$ \\
\hline
\end{tabular}

F- female; M- male; A - Arab; J- Jew; C- complement component.

Mean age at presentation was $8.46(2.5-14)$ years. Clinical manifestations in all patients consisted of meningococcal meningitis with or without meningococcemia. Neurological complications included abducens nerve palsy (P3), white matter lesions of the pons (P1), and neurosensory hearing loss (P5). Mean delay between clinical presentation and diagnosis was $10.56(0-30)$ years. Notably, P5 was diagnosed 30 years after his initial meningococcal infection.

\section{Immune work-up}

Asplenia was ruled out in all patients. The work-up of the complement pathway is presented in Table 2, demonstrating nearly absent levels of CH50, compatible with a classic complement pathway defect. Detailed measures of the complement pathway were available for four patients and yielded reduced levels of C6 (P1 and P2), C7 (P3 and P4), and C8 (P5). 
Table 2

Complement component levels of the patients

\begin{tabular}{|c|c|c|c|c|c|c|}
\hline Complement components & $\begin{array}{l}\text { P1 } \\
\text { (18 years) }\end{array}$ & $\begin{array}{l}\text { P2 } \\
\text { (24 years) }\end{array}$ & $\begin{array}{l}\text { P3 } \\
\text { (16 years) }\end{array}$ & $\begin{array}{l}\text { P4 } \\
\text { (9.5 years) }\end{array}$ & $\begin{array}{l}\text { P5 } \\
\text { (37 years) }\end{array}$ & Normal range \\
\hline CH50 (U/mL) & 3 & 2 & 0 & 0 & 0 & $60-144$ \\
\hline $\mathrm{C} 1 \mathrm{q}(\mathrm{mg} / \mathrm{dL})$ & 16 & 20 & 20 & NA & 14.8 & $12.6-20.8$ \\
\hline $\mathrm{C} 2(\mathrm{mg} / \mathrm{dL})$ & 1.7 & 2.2 & 3.8 & NA & 2.4 & $1.8-3$ \\
\hline C3 (mg/dL) & 112 & 98.9 & 163 & NA & 123 & $90-180$ \\
\hline $\mathrm{C} 4(\mathrm{mg} / \mathrm{dL})$ & 20.2 & 28.1 & 27.8 & NA & 18.8 & $10-40$ \\
\hline C5 $(\mathrm{mg} / \mathrm{dL})$ & 11 & 14 & 20 & NA & $>20$ & $12.4-19.2$ \\
\hline $\mathrm{C} 6(\mathrm{mg} / \mathrm{dL})$ & $<0.6$ & $<0.6$ & $>12$ & NA & 11.3 & $8.0-13.2$ \\
\hline $\mathrm{C} 7(\mathrm{mg} / \mathrm{dL})$ & 7.3 & 11 & 0 & NA & 6.5 & $5.9-9.5$ \\
\hline $\mathrm{C} 8(\mathrm{mg} / \mathrm{dL})$ & 20 & 18 & $>20$ & NA & 6.2 & $12-18.4$ \\
\hline $\mathrm{C} 9(\mathrm{mg} / \mathrm{dL})$ & 31 & 38 & 45 & NA & $>50$ & $23.6-45.8$ \\
\hline Total (\%) & Traces & Traces & NA & NA & Traces & $40-100$ \\
\hline
\end{tabular}

NA- data is not available; $\mathrm{CH} 50-50 \%$ hemolytic complement activity of serum; C- complement component; In bold - values above normal range; Italicsvalues below normal range.

\section{Genetic work-up}

WES revealed a novel homozygous mutation in C6 (c.1786C > T; p.R596X) in P1 and P2 (Fig. 2A). A mutation in C7 (c.1135G > C; p.G379R) was identified in P3 and P4 (Fig. 2B). P5 had a novel homozygous mutation in C8b (c.361C > T; p.R121X, Fig. 2C). Interestingly, P5 also had a homozygous mutation in CECAM16 (c.703C > T; p.R235C), which is related to hearing loss [11].These variants were considered rare and pathogenic by different predictive software. Sanger sequencing confirmed the genetic findings with Mendelian inheritance yielding heterozygous carriers among first-degree relatives, including parents and siblings.

\section{Treatment and outcome}

All patients were prescribed extended meningococcal vaccines and prophylactic amoxicillin. Interestingly, prior to the diagnosis of her $\mathrm{C} 6$ deficiency, P2 received prophylactic amoxicillin due to rheumatic fever. This may account for her 18-year delay in diagnosis.

The mean current patient age is $24(16-37)$ years. Only one patient (P5) has demonstrated residual neurological impairment in the form of neurosensory hearing loss, which may have complicated his primary genetic hearing loss defect.

\section{Discussion}

In this study, we described our experience with primary complement component deficiencies. Using WES, we identified three novel mutations in $C 6, C 7$ and $C 8 b$ and confirmed the diagnosis by quantifying $\mathrm{CH} 50$ and different components of the classical pathway. Two patients (P1 and P2) with meningococcemia were found to have a novel genetic mutation causing C6 deficiency. C6 interacts with C5b, C7, C8, and C9 to form the membrane attack complex, which catalyzes cell lysis [12]. Terminal complement component deficiencies (C5-C9) are associated with an up to 10,000-fold increased risk of invasive meningococcal infection [4]. High prevalence of C6 deficiency has mainly been reported among the African-American population [12], though it is also seen in other ethnicities, such as Spanish [13], Irish [14], and South-African [14].

Our study found a significant delay in diagnosis from the initial meningococcal infection. Diagnosis of C6 and C8b deficiencies in P2 and P5 was delayed by 18 and 30 years, respectively. Interestingly, prophylactic amoxicillin given to P2 due to rheumatic fever may also have a role in the delayed diagnosis due to lack of meningococcal infections while P2 was on prophylactic treatment. This further demonstrates the need for a high index of suspicion in patients with a single meningococcal infection episode.

Our report corresponds with other studies. In one study of 22 adult patients who previously experienced a single event of meningococcal meningitis, 2 were diagnosed with $\mathrm{C} 6$ and $\mathrm{C} 7$ deficiencies [3]. In South Africa, $12.8 \%$ of patients with invasive meningococcal infections have been found to have $\mathrm{C} 5$ and $\mathrm{C} 6$ deficiencies [15].

However, screening all children presenting with a single invasive meningococcal disease for complement deficiencies is costly and has not been routinely implemented, therefore investigation is directed by diagnostic clues. The presence of consanguinity, a family history of meningococcal infections, and recurrent episodes of invasive meningococcal infection are obvious "red flags" that indicate a need for investigation. Grumach et al. detailed other signs of complement deficiency, including meningococcal meningitis in a patient > 5 years old; meningococcal infections with less common serotypes; the presence of autoimmune disease, such as SLE; angioedema without urticaria; other recurrent bacterial infections; and renal and ophthalmic involvement in complement regulatory protein deficiencies, including factor $\mathrm{H}$ deficiency in hemolytic uremic syndrome [1]. 
The patients in our cohort presented with a single meningococcal meningitis event with or without meningococcemia. The family history and consanguinity in families $A, C$, and D were indicators to start immune and genetic work-up. Furthermore, identification of meningococcal serotype $Y$ in P1 and P2 was also a clue, as the most common serotypes reported in Israel are B and C (76.9\% and $10.9 \%$, respectively)[16].

Use of $\mathrm{CH} 50$ screening complemented by WES enhanced the diagnosis of some of our patients. We suggest implementing this methodology in patients with a single invasive meningococcal infection as a "red flag" for primary inborn errors of immunity to reduce the diagnostic delay. This will facilitate better patient care, decrease rates of neurological complications and promote early genetic counselling of siblings.

Our study has several limitations, particularly its size and retrospective design. Prospective large cohort studies investigating complement deficiencies using WES and $\mathrm{CH} 50$ screening in patients with a single meningococcal infection are needed.

In conclusion, management of a patient with a first invasive meningococcal infection requires awareness of complement component deficiencies. Upon clinical signs, prompt immune and genetic investigations should be recommended, commencing diagnosis and proper treatment.

\section{List Of Abbreviations}

AH50 - Alternative pathway hemolytic assay

C - Complement component

CH50 - 50\% hemolytic complement activity of serum

PID - Primary immune deficiency

SLE - Systemic lupus erythematosus

WES - Whole exome sequencing

\section{Declarations}

Acknowledgments None.

Funding: None.

Conflicts of interest: The authors declare that they have no conflicts of interest.

Availability of data and material: non-applicable.

Code availability: non-applicable.

Authors' contributions: OS- study design, data collection and analysis, and writing of the manuscript; AJS- genetic analysis and figure formation; SF- data collection; TS- manuscript revisions; OM- medical care of the patients and manuscript revision; OB- genetic analysis; RS and YT- immune consultation and manuscript revisions; OT- study design and supervision, medical care of the patients, manuscript revisions.

Ethics approval: This study was approved by the institutional review board committees of Shaare Zedek and Tel-Hashomer Medical Centers.

Consent to participate: non-applicable.

Consent for publication: non-applicable.

Clinical trials registration: non-applicable.

\section{References}

1. Grumach AS, Kirschfink M (2014) Are complement deficiencies really rare? Overview on prevalence, clinical importance and modern diagnostic approach. Mol Immunol 61:110-117

2. Bousfiha A, Jeddane L, Picard C, Ailal F, Bobby Gaspar H, Al-Herz W, Chatila T, Crow YJ, Cunningham-Rundles C, Etzioni A, Franco JL, Holland SM, Klein C, Morio T, Ochs HD, Oksenhendler E, Puck J, Tang MLK, Tangye SG, Torgerson TR, Casanova JL, Sullivan KE (2018) The 2017 IUIS Phenotypic Classification for Primary Immunodeficiencies. J Clin Immunol 38:129-143

3. Sanges S, Wallet F, Blondiaux N, Theis D, Verin I, Vachee A, Dessein R, et al. (2017) Diagnosis of primary antibody and complement deficiencies in young adults after a first invasive bacterial infection. Clin Microbiol Infect 23:576 e571-576 e575

4. Rosenfield L, Cvetkovic A, Woodward K, Quirt J (2018) Late presentation of subtotal C6 deficiency in a patient with recurrent Neisseria meningitides infections. Ann Allergy Asthma Immunol 120:432-433

5. Simon AJ, Golan AC, Lev A, Stauber T, Barel O, Somekh I, Klein C, AbuZaitun O, Eyal E, Kol N, Unal E, Amariglio N, Rechavi G, Somech R (2020) Whole exome sequencing (WES) approach for diagnosing primary immunodeficiencies (PIDs) in a highly consanguineous community. Clin Immunol 214:108376 
6. Demirkaya E, Zhou Q, Smith CK, Ombrello MJ, Deuitch N, Tsai WL, Hoffmann P, Remmers EF, Takeuchi M, Park YH, Chae J, Barut K, Simsek D, Adrovic A, Sahin S, Caliskan S, Chandrasekharappa SC, Hasni SA, Ombrello AK, Gadina M, Kastner DL, Kaplan MJ, Kasapcopur O, Aksentijevich I (2017) Brief Report: Deficiency of Complement 1r Subcomponent in Early-Onset Systemic Lupus Erythematosus: The Role of Disease-Modifying Alleles in a Monogenic Disease. Arthritis Rheumatol 69:1832-1839

7. Zoghi S, Ziaee V, Hirschmugl T, Jimenez-Heredia R, Krolo A, Boztug K, Rezaei N (2018) Exome sequencing revealed C1Q homozygous mutation in Pediatric Systemic Lupus Erythematosus. Allergol Immunopathol (Madr) 46:594-598

8. Li H (2013) Aligning sequence reads, clone sequences and assembly contigs with BWA-MEM. arXiv:1303.3997v1 [q-bio.GN].

9. DePristo MA, Banks E, Poplin R, Garimella KV, Maguire JR, Hartl C, Philippakis AA, del Angel G, Rivas MA, Hanna M, McKenna A, Fennell TJ, Kernytsky AM, Sivachenko AY, Cibulskis K, Gabriel SB, Altshuler D, Daly MJ (2011) A framework for variation discovery and genotyping using next-generation DNA sequencing data. Nat Genet 43:491-498

10. Li M, Li J, Li MJ, Pan Z, Hsu JS, Liu DJ, Zhan X, Wang J, Song Y, Sham PC (2017) Robust and rapid algorithms facilitate large-scale whole genome sequencing downstream analysis in an integrative framework. Nucleic Acids Res 45:e75

11. Booth KT, Kahrizi K, Najmabadi H, Azaiez H, Smith RJ (2018) Old gene, new phenotype: splice-altering variants in CEACAM16 cause recessive nonsyndromic hearing impairment. J Med Genet 55:555-560

12. Zhu Z, Atkinson TP, Hovanky KT, Boppana SB, Dai YL, Densen P, Go RC, Jablecki JS, Volanakis JE (2000) High prevalence of complement component C6 deficiency among African-Americans in the south-eastern USA. Clin Exp Immunol 119:305-310

13. Moya-Quiles MR, Bernardo-Pisa MV, Martinez P, Gimeno L, Bosch A, Salgado G, Martinez-Banaclocha H, Eguia J, Campillo JA, Muro M, Vidal-Bugallo JB, Alvarez-Lopez MR, Garcia-Alonso AM (2013) Complement component C6 deficiency in a Spanish family: implications for clinical and molecular diagnosis. Gene 521:204-206

14. Parham KL, Roberts A, Thomas A, Wurzner R, Henderson HE, Potter PC, Morgan BP, Orren A (2007) Prevalence of mutations leading to complete C6 deficiency (C6Q0) in the Western Cape, South Africa and detection of novel mutations leading to C6Q0 in an Irish family. Mol Immunol 44:2756-2760

15. Owen EP, Leisegang F, Whitelaw A, Simpson J, Baker S, Wurzner R, Potter P, Orren A (2012) Complement component C5 and C6 mutation screening indicated in meningococcal disease in South Africa. S Afr Med J 102:525-527

16. Ben-Shimol S, Dagan R, Schonmann Y, Givon-Lavi N, Keller N, Block C, Kassis I, Ephros M, Greenberg D (2013) Dynamics of childhood invasive meningococcal disease in Israel during a 22-year period (1989-2010). Infection 41:791-798

\section{Figures}

\section{A}

Heterzygous $\square$ Homozygous to 66 mutation

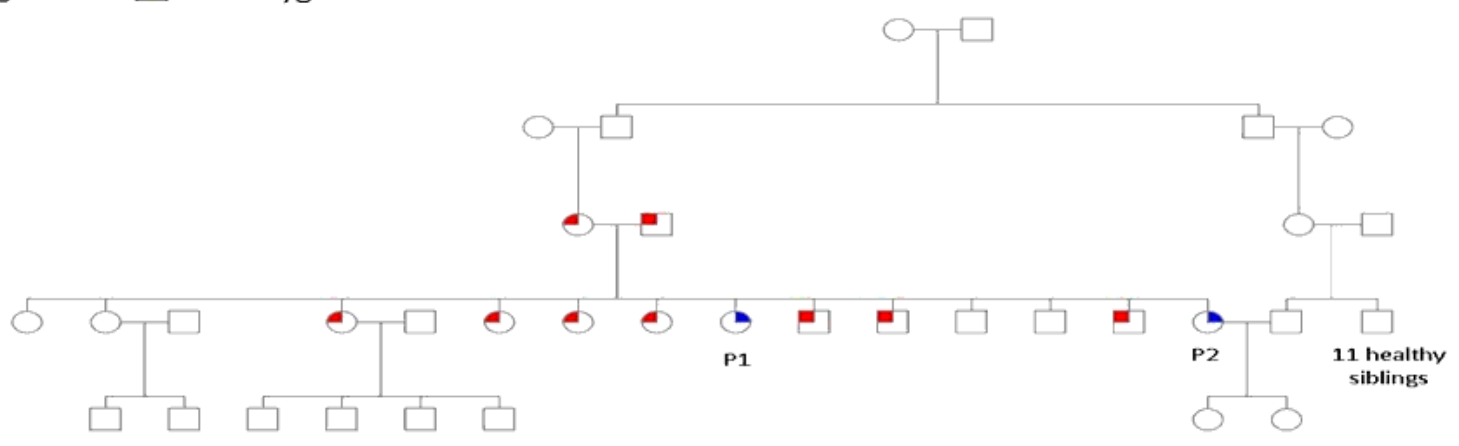

B

$\square^{\text {Heterozygous }} \quad \square$ Homozygous to C8b mutation

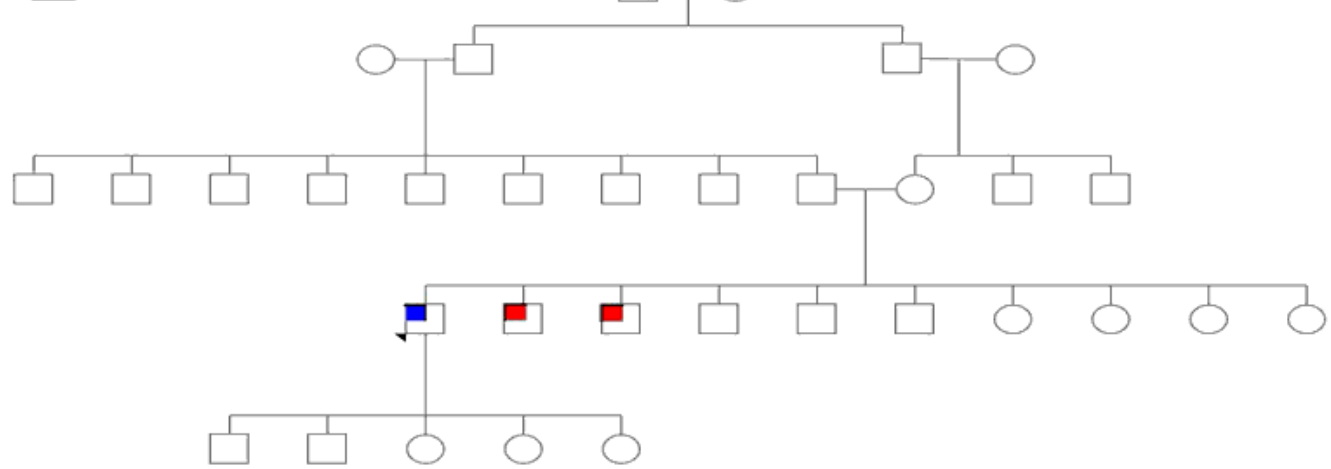

Page 6/7 
Figure 1

(A, B) Pedigrees of families A (P1, 2) and D (P5), respectively. Notable are consanguinity and heterozygous carriers.

A

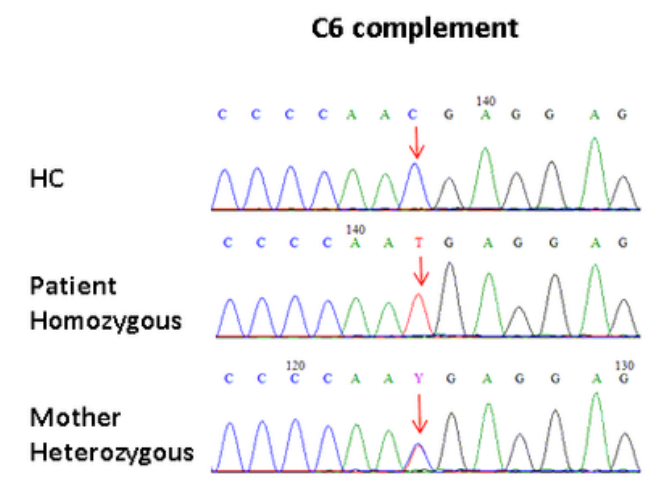

Exon 12 c.1786C $>$ T; p.R596X
B

C7 complement

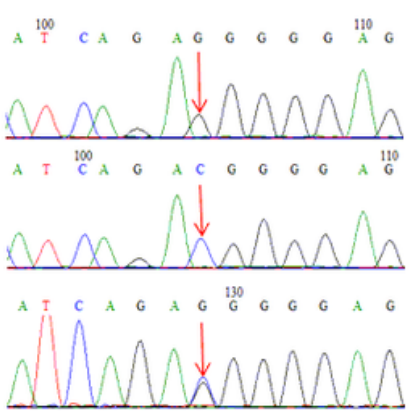

Exon 10 c.1135G>C; p.G379R
C

C8b complement

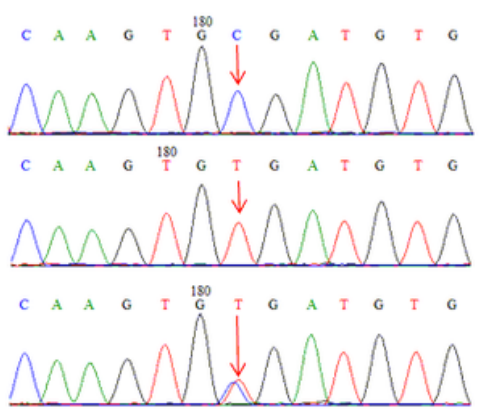

Exon 3 c.361C>T; p.R121X

Figure 2

(A, B, C) Chromatograms of P1, P4 and P5 demonstrative of novel mutations in the complement components C6, C7 and C8b, respectively. HC- Healthy control. 